\title{
TATA KELOLA PERBANKAN DITINJAU DARI KINERJA KEUANGAN DILIHAT DARI PROFITABILITAS
} PERBANKAN

\author{
Eko Meiningsih Susilowati \\ susilowatieko@stie-aub.ac.id \\ Erna Tiningrum \\ ernatiningrum@stie-aub.ac.id
}

\begin{abstract}
ABSTRAK
Penelitian ini bertujuan untuk menguji pengaruh Capital Adequacy Ratio (CAR), Non Performing Loan (NPL), Biaya Operasional pada Pendapatan Operasional (BOPO) dan Loan to Deposit Ratio (LDR) terhadap Return on Asset (ROA) pada bank umum konvensional yang terdaftar di Bursa Efek Indonesia periode 2014-2016. Populasi dalam penelitian ini adalah bank umum konvensional yang terdaftar di Bursa Efek Indonesia. Sampel yang digunakan adalah bank umum konvensional yang terdaftar di bursa efek Indonesia tahun 2014-2016. Teknik pengambilan sampel menggunakan purposive sampling. Analisis data menggunakan regresi linier berganda. Hasil penelitian menunjukkan bahwa Capital Adequacy Ratio berpengaruh positif tetapi tidak signifikan terhadap Return on Asset, Non Performing Loan berpengaruh positif tetapi tidak signifikan terhadap Return on Asset, Rasio Biaya Operasional terhadap Pendapatan Operasional berpengaruh positif dan signifikan terhadap Return on Asset dan Loan to Deposit Ratio berpengaruh positif dan signifikan terhadap Return on Asset. Hasil uji adjusted $\mathrm{R}^{2}$ pada penelitian ini diperoleh nilai sebesar 0,395. Hal ini menunjukkan bahwa profitabilitas dipengaruhi oleh capital adequacy ratio (CAR), non performing loan (NPL), biaya operasional pada pendapatan operasional (BOPO) dan loan to deposit ratio (LDR) sebesar 39,5\%, sedangkan sisanya sebesar $60,5 \%$ dipengaruhi oleh faktor lain yang tidak diteliti dalam penelitian ini.
\end{abstract}

Kata kunci: CAR, NPL, BOPO, LDR dan ROA.

\section{A. PENDAHULUAN}

Pertumbuhan ekonomi suatu bangsa memerlukan pola pengaturan pengolahan sumber-sumber ekonomi yang tersedia secara terarah dan terpadu serta dimanfaatkan bagi peningkatan kesejahteraan masyarakat. Lembagalembaga perekonomian bahu-membahu mengelola dan menggerakkan semua potensi ekonomi agar berguna secara optimal. Lembaga keuangan, khususnya lembaga perbankan mempunyai peranan yang amat strategis dalam menggerakkan roda perekonomian suatu Negara. Perusahaan yang melakukan kegiatan menyediakan jasa keuangan bagi seluruh lapisan masyarakat dikenal dengan nama bank. Fungsi utama bank secara umum adalah menghimpun dana dari masyarakat dan menyalurkannya kembali kepada masyarakat untuk berbagai tujuan atau sebagai financial intermediary.

Profitabilitas merupakan indikator yang paling tepat untuk mengukur kinerja suatu bank. Ukuran profitabilitas yang digunakan adalah Return on Asset (ROA). Return On Asset (ROA), yaitu rasio yang

digunakan untuk mengukur kemampuan manajemen bank dalam memperoleh keuntungan (laba) secara keseluruhan Alifah (2014). Laba yang besar akan menarik investor karena perusahaan memiliki tingkat pengembalian yang semakin tinggi. Mengacu pada Surat Edaran Bank Indonesia dimana ROA didefinisikan sebagai berikut:

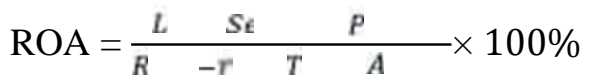

Capital Adequacy Ratio (CAR) adalah kecukupan modal yang menunjukkan kemampuan bank dalam mempertahankan modal yang mencukupi dan kemampuan manajemen bank dalam mengidentifikasi, mengukur, mengawasi, dan mengontrol risiko-risiko yang timbul yang dapat berpengaruh terhadap besarnya modal. Perhitungan Capital Adequacy Ratio didasarkan pada prinsip bahwa setiap penanaman yang mengandung risiko harus disediakan jumlah modal sebesar persentase tertentu terhadap jumlah penanamannya Arifianto (2016). Sesuai dengan penilaian rasio CAR berdasarkan Surat Keputusan DIR BI No. 30/12/KEP/DIR tanggal 30 April 1997 CAR minimal 8\%. 
Perhitungan rasio CAR adalah sebagai berikut :

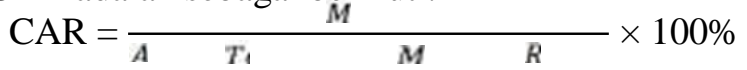

Pinjaman yang mengalami kesulitan pelunasan akibat adanya faktor kesengajaan dan atau karena faktor eksternal di luar kemampuan kendali debitur sering disebut dengan kredit bermasalah atau Non Performing Loan (NPL). Risiko kredit ini dapat terjadi akibat kegagalan dan ketidakmampuan nasabah dalam mengembalikan sejumlah pinjaman yang diterima dari bank beserta bunganya sesuai dengan jangka waktu yang telah ditentukan atau dijadwalkan Amalia (2010). NPL mencerminkan risiko kredit, semakin kecil NPL semakin kecil pula risiko kredit yang ditanggung pihak bank. Agar nilai bank terhadap rasio ini baik Bank Indonesia menetapkan kriteria rasio NPL di bawah $5 \%$. Perhitungan rasio NPL dapat dihitung dengan rumus :

$$
\mathrm{NPL}=\frac{K{ }_{B} \quad h}{T \quad K} \times 100 \%
$$

Rasio biaya operasional adalah perbandingan antara biaya operasional dan pendapatan operasional. Rasio biaya operasional digunakan untuk mengukur tingkat efisiensi dan kemampuan bank dalam melakukan kegiatan operasi . BOPO menurut kamus keuangan adalah kelompok rasio yang mengukur efisiensi dan efektivitas operasional suatu perusahaan dengan jalur membandingkan satu terhadap lainnya. Berbagai angka pendapatan dan pengeluaran dari laporan rugi laba dan terhadap angka-angka dalam neraca Ariyani (2010). Semakin kecil rasio BOPO menunjukkan semakin efisien suatu bank dalam menjalankan aktivitas usahanya. Perhitungan rasio BOPO dapat dihitung dengan rumus :

$$
\mathrm{BOPO}=\frac{B \quad O}{P_{1}} \times 100 \%
$$

Loan to Deposit Ratio (LDR) adalah suatu pengukuran tradisional yang menunjukkan deposito berjangka, giro, tabungan, dan lain-lain yang digunakan dalam memenuhi permohonan pinjaman (loan requests) nasabahnya. Rasio ini digunakan untuk mengukur tingkat likuiditas. Rasio yang tinggi menunjukkan bahwa suatu bank meminjamkan seluruh dananya (loan-up) atau relatif tidak likuid (illiquid). Sebaliknya rasio yang rendah menunjukkan bank yang likuid dengan kelebihan kapasitas dana yang siap untuk dipinjamkan Hapsari (2011). Rasio ini juga merupakan indikator kerawanan dan kemampuan dari suatu bank. Sebagian praktisi perbankan menyepakati bahwa batas aman dari Loan to Deposit Rasio suatu bank adalah sekitar 80\%. Namun, batas toleransi berkisar antara $85 \%$ sampai $100 \%$. Perhitungan rasio LDR dapat dihitung dengan rumus :

$$
\mathrm{LDR}=\frac{\hbar h_{K} \quad y a d_{i}}{T \quad D \quad P a K} \times 100 \%
$$

Beberapa penelitian yang berkaitan dengan Return On Asset (ROA) sebagai proksi dari profitabilitas bank pun menunjukkan hasil yang berbeda-beda. Berdasarkan penelitian yang diteliti oleh (Wibowo \& Syaichu, 2013), variabel CAR berpengaruh negatif tetapi tidak signifikan terhadap Profitabilitas. (Putrianingsih \& Yulianto, 2016) dan (Winastri, Andini, \& Raharjo, 2017a) juga meneliti bahwa CAR berpengaruh negatif terhadap ROA. Hasil penelitian tersebut bertentangan dengan penelitian yang dilakukan oleh (Arifianto, 2016) yang menunjukkan CAR berpengaruh positif dan signifikan terhadap profitabilitas.

Hasil penelitian mengenai pengaruh Non Performing Loan (NPL) terhadap Profitabilitas. (Putrianingsih \& Yulianto, 2016) dan (Winastri, Andini, \& Raharjo, 2017) menunjukkan variabel Non

Performing Loan (NPL) berpengaruh negatif terhadap Return on Asset (ROA). Hasil penelitian tersebutbertentangan dengan penelitian yang dilakukan oleh (Robin, 2013) yang menunjukkan NPL berpengaruh positif dan signifikan terhadap profitabilitas.

Hasil penelitian mengenai pengaruh BOPO terhadap Profitabilitas. (Ariyani, 2010) menunjukkan variabel BOPO berpengaruh positif terhadap Return on Asset (ROA). Hasil penelitian tersebut bertentangan dengan penelitian yang dilakukan oleh (Wibowo \& Syaichu, 2013) dan (Yogi Prasanjaya \& Ramantha, 2013) yang menunjukkan variabel BOPO berpengaruh negatif dan signifikan terhadap ROA.

Hasil penelitian mengenai pengaruh Loan to Deposit Ratio (LDR) terhadap Profitabilitas. (Winastri,

Andini, \& Raharjo, 2017) menunjukkan variabel LDR berpengaruh negatif terhadap Return on Asset (ROA). Hasil penelitian tersebut bertentangan dengan penelitian yang dilakukan oleh (Arifianto, 2016) yang menunjukkan LDR berpengaruh positif terhadap terhadap Return on Asset (ROA). 
Berdasarkan latar belakang di atas, maka tujuan dalam penelitian ini adalah untuk mengetahui dan menguji pengaruh Capital Adequacy Ratio (CAR) terhadap Return on Asset (ROA), pengaruh Non

Performing Loan (NPL) terhadap Return on Asset (ROA), pengaruh Biaya Operasional Pendapatan

Operasional (BOPO) terhadap Return on Asset (ROA) dan pengaruh Loan to Deposit Ratio (LDR) terhadap Return on Asset (ROA).

\section{B. METODE}

Populasi dalam penelitian ini adalah seluruh perusahaan perbankan yang terdaftar di Bursa Efek Indonesia (BEI) dengan sampel yang digunakan adalah perusahaan perbankan yang terdaftar di Bursa Efek Indonesia (BEI) periode pengamatan selama 3 tahun yaitu tahun 2014- 2016 sehingga diperoleh sampel sebanyak 24 sampel. Teknik pengambilan sampel yang digunakan dalam penelitian ini menggunakan teknik purposive sampling.

Variabel dalam penelitian ini adalah Capital Adequacy Ratio (X1), Non Performing Loan (X2), Biaya Operasional Pendapatan Operasional (X3), Loan to Deposit Ratio (X4) dan Return on Assets (Y). Penelitian ini menggunakan Analisis Regresi Linier Berganda. Tahap yang dilakukan adalah uji asumsi klasik, uji t, uji F dan uji $\mathrm{R}^{2}$.

B. Hasil penelitian

Dari hasil analisis statistik diperoleh output penelitian sebagai berikut:

1. Uji Asumsi Klasik

a. Uji Normalitas

Tabel 1

Hasil Uji Normalitas

\begin{tabular}{|c|c|c|c|c|c|c|}
\hline \multicolumn{7}{|c|}{ One-Sample Kolmogorov-Smirnov Test } \\
\hline & & CAR & NPL & BOPO & LDR & \\
\hline $\mathrm{N}$ & & 72 & 72 & 72 & 72 & 72 \\
\hline Normal Parametês & $\begin{array}{l}\text { Mean } \\
\text { Std Deviation }\end{array}$ & $\begin{array}{l}19,1907 \\
512461\end{array}$ & $\begin{array}{r}2,1807 \\
133380\end{array}$ & $\begin{array}{r}4,4693 \\
, 7091\end{array}$ & $\begin{array}{r}82,1082 \\
12,1552\end{array}$ & .3251 \\
\hline & Absolute & 5,12461 & 1,38380 & $\begin{array}{r}.27081 \\
.155\end{array}$ & 12,15543 & ,95973 \\
\hline \multirow{2}{*}{ coes } & Pos & 143 & .103 & .155 & .079 & .051 \\
\hline & Negative & -.096 & -.074 & -.147 & -.151 & -.081 \\
\hline \multicolumn{2}{|l|}{ Kolmos } & 1,210 & .873 & 1,314 & 1280 & 690 \\
\hline \multicolumn{2}{|l|}{ Asymp. Sig. (2-tailed) } & 107 & .430 & .063 & .076 & .728 \\
\hline
\end{tabular}

Hasil uji normalitas variabel penelitian menunjukkan bahwa residual mempunyai nilai signifikansi lebih besar dari 0,05 pada (sig>0,05), sehingga dapat disimpulkan bahwa residual berdistribusi normal.

b. Uji Multikolinearitas

Tabel 2

Hasil Uji Multikolinearitas

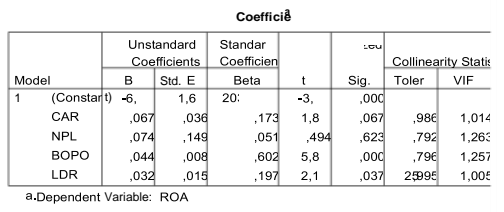

Tabel di atas menunjukkan bahwa semua variabel bebas mempunyai nilai toleransi di atas 0,1 dan nilai VIF di bawah 10, sehingga dapat disimpulkan bahwa model regresi pada penelitian ini tidak terjadi multikolinearitas.

c. Uji Heteroskedastisitas

Tabel 3

Hasil Uji Heteroskedastisitas coefticieents

\begin{tabular}{|c|c|c|c|c|c|}
\hline \multirow[b]{2}{*}{ Model } & \multicolumn{2}{|c|}{\begin{tabular}{|l|} 
Unstandardized \\
Coefficients
\end{tabular}} & \multirow{2}{*}{\begin{tabular}{|l|l|} 
Standardi \\
Coefficients \\
Beta \\
\end{tabular}} & & \multirow[b]{2}{*}{ Sig. } \\
\hline & $B$ & Std. Er & & & \\
\hline \multirow{5}{*}{$\begin{array}{|lr|}1 & \text { Constant } \\
\text { CAR NPL BOPO } \\
\text { LDR } & \\
\end{array}$} & & .915 & & -154 & \begin{tabular}{|l|}
, 878 \\
\end{tabular} \\
\hline & 141 & .020 & 098 & .812 & 420 \\
\hline & .016 & .084 & 095 & .704 & 484 \\
\hline & .059 & .004 & 047 & .347 & 730 \\
\hline & & T & 133 & 1,111 & .270 \\
\hline
\end{tabular}

Berdasarkan uji Glejser yang telah dilakukan menunjukkan bahwa tidak ada satupun variabel independen yang signifikan secara statistik memengaruhi variabel dependen nilai absolute Residual (ABS_RES). 
Hal ini terlihat dari probabilitas signifikansinya di atas tingkat kepercayaan 5\%. Jadi dapat disimpulkan model regresi tidak mengandung heteroskedastisitas.

d. Uji Autokolerasi

Tabel 4

Hasil Uji Autokolerasi

\begin{tabular}{|l|r|r|r|r|r|}
\hline \multicolumn{7}{|c|}{ Model Summary } \\
\hline Mod & $R$ & R Squ & $\begin{array}{c}\text { Adjust } \\
\text { R Squar }\end{array}$ & $\begin{array}{c}\text { Std. Error } \\
\text { the Esti }\end{array}$ & $\begin{array}{r}\text { Durbin- } \\
\text { Watson }\end{array}$ \\
\hline 1 &, 655 &, 429 &, 395 & 1,544 & 1,734 \\
\hline
\end{tabular}

Berdasarkan hasil perhitungan nilai Durbin-Watson sebesar 1,734 yang berarti nilainya diantara $\mathrm{dl}<\mathrm{dw}<\mathrm{du}$ dimana $\mathrm{dl}=1,5029 \mathrm{dan} \mathrm{du}=1,7366$. Hal ini menunjukan tidak ada autokolerasi.

Tabel 5

Hasil Uji Regresi Linier berganda

\begin{tabular}{|c|c|c|c|c|c|}
\hline \multicolumn{6}{|c|}{ Coefficients } \\
\hline \multirow[b]{2}{*}{ Model } & \multicolumn{2}{|c|}{$\begin{array}{l}\text { Unstandardized } \\
\text { Coefficients }\end{array}$} & \multirow{2}{*}{\begin{tabular}{|l|}
$\begin{array}{l}\text { Standardized } \\
\text { Coefficients }\end{array}$ \\
Beta \\
\end{tabular}} & \multirow[b]{2}{*}{ t } & \multirow[b]{2}{*}{ Sig. } \\
\hline & $B$ & Std. Error & & & \\
\hline (Constant) CAR & 6,203 & 1,625 & & $-3,817$ & .000 \\
\hline \multirow[t]{4}{*}{ NPL BOPO LDR } & .067 & .036 & .173 & 1,862 & .067 \\
\hline & .074 & .149 & .051 & .494 & .623 \\
\hline & .044 & .008 & .602 & 5,815 & .000 \\
\hline & .032 & .015 & .197 & 2,125 & .037 \\
\hline
\end{tabular}

C. Analisis Regresi

Persamaan Regresi:

$\mathrm{ROA}=-6,203+0,067 \mathrm{CAR}+0,074 \mathrm{NPL}+0,044 \mathrm{BOPO}+0,032 \mathrm{LDR}$

Berdasarkan hasil uji statistik t pada tabel diatas dapat diimplementasikan sebagai berikut:

1) Pengaruh capital adequacy ratio terhadap return on asset diperoleh nilai signifikasi capital adequacy ratio sebesar 0,067 > 0,05 menunjukan bahwa capital adequacy ratio berpengaruh positif tetapi tidak signifikan terhadap return on asset. (hipotesis 1 diterima).

2) Pengaruh Non Performing Loan terhadap return on asset diperoleh nilai signifikasi non performing loan sebesar 0,623>0,05 menunjukan bahwa non performing loan berpengaruh positif tetapi tidak signifikan terhadap return on asset.(hipotesis 2 diterima).

3) Pengaruh Biaya Operasional Pendapatan Operasional terhadap return on asset diperoleh nilai signifikasi biaya operasinal pendapatan operasional sebesar $0,000<0,05$ menunjukan bahwa biaya operasional pendapatan operasional berpengaruh positif dan signifikan terhadap return on asset.(hipotesis 3 diterima).

4) Pengaruh Loan to Deposit Ratio terhadap return on asset diperoleh nilai signifikasi loan to deposit ratio sebesar $0,037<0,05$ menunjukan bahwa loan to deposit ratio berpengaruh positif dan signifikan terhadap return on asset. (hipotesis 4 diterima).

Tabel 6

Hasil Uji Koefisien Determinasi $\left(\mathrm{R}^{2}\right)$

\begin{tabular}{l|r|r|r|r|r}
\multicolumn{7}{c}{ Model Summatry } \\
\hline Model & R & R Square & $\begin{array}{r}\text { Adjusted } \\
\text { R Square }\end{array}$ & $\begin{array}{c}\text { Std. Error } \\
\text { the Estima }\end{array}$ & $\begin{array}{c}\text { Durbin- } \\
\text { Watson }\end{array}$ \\
\hline 1 &, 659 &, 429 &, 395 & 1,54432 & 1,734 \\
\hline
\end{tabular}

Hasil uji adjusted $\mathrm{R}^{2}$ pada penelitian ini diperoleh nilai sebesar 0,395. Hal ini menunjukkan bahwa profitabilitas dipengaruhi oleh capital adequacy ratio (CAR), non performing loan (NPL), biaya operasional pada pendapatan operasional (BOPO) dan loan to deposit ratio (LDR) sebesar 39,5\%, sedangkan sisanya sebesar 60,5\% dipengaruhi oleh faktor lain yang tidak diteliti dalam penelitian ini misalnya Deposit Risk Ratio (DRR), Quick Ratio dan Leverage Multipleyer. 


\section{PEMBAHASAN}

1. Capital adequacy ratio berpengaruh positif tetapi tidak signifikan terhadap return on asset.

Hasil penelitian ini mendukung hasil penelitian sebelumnya yang dilakukan oleh Arifianto (2016), meskipun tidak signifikan hasil dari penelitian ini adalah variabel Capital Adequacy Ratio (CAR) mempunyai pengaruh positif dan tidak signifikan terhadap Return on Asset.

2. Non performing loan berpengaruh positif tetapi tidak signifikan terhadap return on asset. Hal ini sesuai dengan penelitian Alifah (2014), meskipun tidak signifikan, hasil penelitian tersebut menunjukkan Non Performing Loan berpengaruh positif dan tidak signifikan terhadap Return on Asset.

3. Biaya operasional pada pendapatan operasional berpengaruh positif dan signifikan terhadap return on asset. Hasil penelitian ini sesuai dengan hasil penelitian sebelumnya yang dilakukan oleh Yogi Prasanjaya \& Ramantha (2013), hasil penelitian ini menunjukan Biaya Operasional pada Pendapatan Operasional berpengaruh positif dan signifikan terhadap Return on Asset.

4. Loan to deposit ratio berpengaruh positif dan signifikan terhadap return on asset.

Hasil penelitian ini mendukung hasil penelitian sebelumnya yang dilakukan oleh Arifianto (2016), hasil penelitian ini menunjukan Loan to Deposit Ratio berpengaruh positif dan signifikan terhadap Return on Asset.

\section{E. PENUTUP}

Berdasarkan hasil analisis dan pembahasan yang telah dijelaskan di bab sebelumnya, maka kesimpulan dari penelitian ini adalah:

1. Capital Adequacy Ratio berpengaruh positif dan tidak signifikan terhadap Return on Asset.

2. Non Performing Loan berpengaruh positif dan tidak signifikan terhadap Return on Asset.

3. Biaya Operasional pada Pendapatan Operasional berpengaruh positif dan signifikan terhadap Return on Asset

4. Loan to Deposit Ratio berpengaruh positif dan signifikan terhadap Return on Asset.

5. Capital Adequacy Ratio (CAR), Non Performing Loan (NPL), Biaya Operasional Pendapatan Operasional (BOPO) dan Loan to Deposit Ratio (LDR) secara bersama sama berpengaruh signifikan secara silmutan terhadap profitabilitas pada bank umum konvensional yang terdaftar di bursa efek indonesia tahun 2014-2016.

6. Hasil uji adjusted $\mathrm{R}^{2}$ pada penelitian ini diperoleh nilai sebesar 0,395 . Hal ini menunjukkan bahwa profitabilitas dipengaruhi oleh capital adequacy ratio (CAR), non performing loan (NPL), biaya operasional pada pendapatan operasional (BOPO) dan loan to deposit ratio (LDR) sebesar 39,5\%, sedangkan sisanya sebesar 60,5\% dipengaruhi oleh faktor lain yang tidak diteliti dalam penelitian ini misalnya Deposit Risk Ratio (DRR), Quick Ratio, dan Leverage Multipler.

Berdasarkan kesimpulan diatas, maka dapat disampaikan saran bahwa terdapat pengaruh capital adequacy ratio (CAR), non performing loan (NPL), biaya operasional pada pendapatan operasional

(BOPO) dan loan to deposit ratio (LDR) terhadap profitabilitas. Oleh karena itu, bagi para investor disarankan untuk memperhatikan faktor capital adequacy ratio (CAR), non performing loan (NPL), biaya operasional pada pendapatan operasional (BOPO) dan loan to deposit ratio (LDR) tersebut, agar dapat memperoleh laba maksimal, sehingga tujuan para investor dapat tercapai.

\section{DAFTAR PUSTAKA}

Alifah, yonira bagiani. (2014). Pengaruh CAR, NPL, BOPO, dan LDR Terhadap Profitabilitas Bank (ROA) Pada Perusahaan Perbankan yang Terdaftar Di Bursa Efek Indonesia Periode 2009-2012. Amalia, laila suci. (2010). Pengaruh CAR, NPL, NIM, BOPO, LDR dan PPAP Terhadap Kinerja Rentabilitas Bank.

Arifianto, A. (2016). Pengaruh Capital Adequacy Ratio (CAR), Non Performing Loan (NPL), Biaya

Operasional pada Pendapatan Operasional (BOPO), Loan To Deposit Ratio (LDR) Dan Net Interest margin (NIM) terhadap Profitabilitas Bank Umum Konvensional yang Terdaftar di Bursa Efek I. Universitas Negeri Yogyakarta.

Ariyani, D. (2010). Analisis Pengaruh CAR, FDR, BOPO, dan NPF terhadap Profitabilitas Pada PT Bank Muamalat Indonesia TBK. Universitas Marcubuana Jakarta, 1-28. 
Ghozali, Imam, 2005, Aplikasi Analisis Multivariate dengan Program SPSS, Edisi 3, Semarang: Badan Penerbit Universitas Diponegoro.

Hapsari, tiara kusuma. (2011). Analisis Pengaruh CAR, NPL, BOPO, LDR, GWM, dan Rasio Konsentrasi Terhadap ROA (Studi Empiris Pada Bank Umum yang Listing Di BEI 2005-2009). Putrianingsih, dwi indah, \& Yulianto, A. (2016). Pengaruh Non Performing Loan (NPL) dan Capital

Adequacy Ratio (CAR) terhadap Profitabilitas. Kumpulan Jurnal Dosen - Ekonomikawan, 1(1), 110-115.Santoso, Singgih. 2002. Buku latihan SPSS statistik multivariat / Singgih Santoso. Jakarta: Elek Media Komputindo.

Wibowo, edhi satriyo, \& Syaichu, M. (2013). Analisis pengaruh suku bunga, inflasi, car, bopo, npf terhadap profitabilitas bank syariah, 2, 1-10.

Winastri, raras guspita putri, Andini, R., \& Raharjo, K. (2017). Pengaruh CAR, BOPO, LDR, Ukuran Perusahaan, NPF dan Anggaran Biaya Operasional Terhadap Profitabilitas Pada Bank yang Terdaftar Di Bursa Efek Indonesia Tahun 2010-2015, 23(39870423), 946-952. https://doi.org/10.13989/j.cnki.0517-6611.2015.10.011

Yogi Prasanjaya, A. A., \& Ramantha, I. W. (2013). Analisis Pengaruh Rasio CAR, BOPO, LDR Dan Ukuran Perusahaan Terhadap Profitabilitas Bank Yang Terdaftar Di BEI. Jurnal Akuntansi Universitas Udayana, 41, 2302-8556. 